\title{
Commentary: Will the fourth dimension guide us toward the "perfect" Norwood arch reconstruction?
}

\author{
Minoo N. Kavarana, MD, FACS
}

\author{
From the Section of Pediatric Cardiothoracic Surgery, Medical University of South Carolina, Charleston, SC. \\ Disclosures: Author has nothing to disclose with regard to commercial support. \\ Received for publication March 8, 2019; accepted for publication March 11, 2019; available ahead of print April \\ $16,2019$. \\ Address for reprints: Minoo N. Kavarana, MD, FACS, Section of Pediatric Cardiothoracic Surgery, Medical Uni- \\ versity of South Carolina, Charleston, SC 29425 (E-mail: kavarana@musc.edu). \\ J Thorac Cardiovasc Surg 2019;158:e119-20 \\ $0022-5223 / \$ 36.00$ \\ Copyright (C) 2019 by The American Association for Thoracic Surgery \\ https://doi.org/10.1016/j.jtcvs.2019.03.040
}

Although rapid strides have been made in the short- and medium-term survivals after stage 1 Norwood palliation for single-ventricle disease, long-term survival is limited by the failing Fontan circulation. ${ }^{1}$ Residual coarctation and aortic arch obstruction is common and has been associated with poor long-term single-ventricular function and survival. $^{2}$

Even despite normal 2-dimensional aortic-arch specific parameters on standard echocardiography and cardiac catheterization, studies have demonstrated that abnormal shape, size mismatch, and contour can lead to maladaptive ventriculoaortic interaction and systemic ventricular dysfunction. $^{3} \quad$ Three-dimensional (3D) magnetic resonance imaging (MRI) studies with computational fluid dynamic modeling have shown that even after a successful coarctation repair in patients with 2-ventricle physiology, those who had abnormal arch shapes and contours (ie, a gothic arch) had worse ventricular function than those who had a natural ("Romanesque") shape. ${ }^{4}$ In patients with singleventricle physiology, altered arch morphology was associated with higher Glenn shunt pressures and longer intensive care unit and hospital stays. ${ }^{5}$ According to these previous 3D MRI computational fluid dynamic modeling studies, there is evidence that reconstructed aortic arch morphology is independently associated with ventricular function and late outcomes. 4,5

Although 3D flow models have clear advantages relative to standard 2-dimensional imaging, they are based on theoretic modeling and geometric-flow assumptions. In contrast, 4D flow MRI directly measures actual flow patterns, thus quantifying viscous or abnormal kinetic energy dissipation as a result of frictional forces.

In their article in this issue of the Journal, Schäfer and colleagues ${ }^{6}$ evaluated 4-dimensional flow MRI characteristics to calculate viscous energy losses at the ascending aorta, aortic arch, and descending aorta in 4 patients who had undergone Norwood arch reconstruction, 2 at the preFontan stage and 2 at the post-Fontan stage. ${ }^{6}$ They found

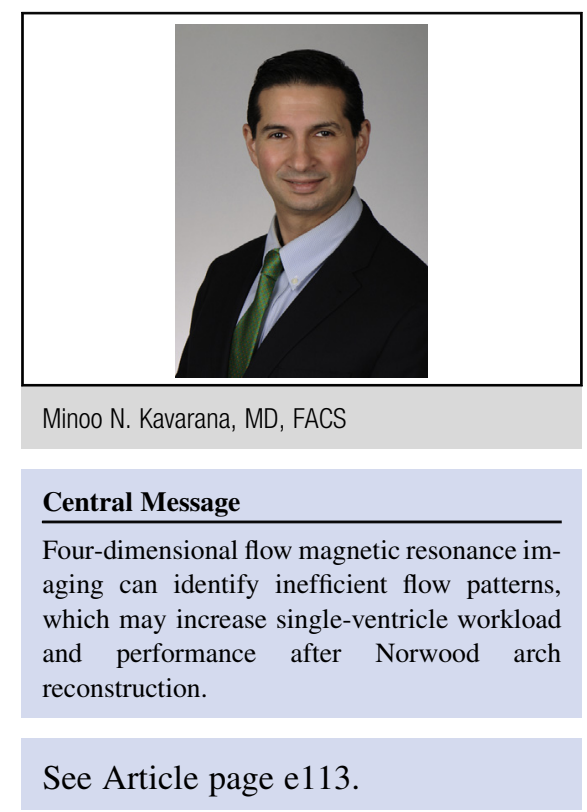

that ascending aortas that were bulky demonstrated diastolic blood pooling and recirculation, with increased viscous energy loss at all 3 levels. A significantly dilated arch with increased size mismatch, where the arch transitions to the descending aorta, was also associated with a high energy loss throughout the aorta. They demonstrated that despite normal aortic arch hemodynamics according to cardiac catheterization and echocardiography, abnormal aortic arch shape and morphology is associated with abnormal flow patterns and energy loss.

Multiple factors determine optimal Norwood arch reconstruction, including the technique, the final shape, and the prosthetic material used, which can result in varying degrees of compliance mismatch with the native aortic tissue. Long-term survival after a Fontan procedure is dependent on good ventricular function, for which an unobstructed systemic ventricular outflow tract is a prerequisite. ${ }^{1}$ To achieve the "ideal" Norwood arch reconstruction, we will need to tailor the arch to patient-specific anatomic variations and dimensions. Use of 4-dimensional flow MRI, which complements 3D MRI with computational fluid dynamic modeling, may help determine preoperatively the size and shape of an ideal aortic arch reconstruction for a specific patient subtype. Along with the growing interest and experience with 3D-printed models for congenital heart defects, advanced imaging techniques may soon be able to 
provide reproducible templates for Norwood arch reconstructions and minimize the incidence of recurrent arch obstruction, late ventricular dysfunction, and Fontan failure.

\section{References}

1. Lee MG, Brizard CP, Galati JC, Iyengar AJ, Rakhra SS, Konstantinov IE, et al. Outcomes of patients born with single-ventricle physiology and aortic arch obstruction: the 26-year Melbourne experience. J Thorac Cardiovasc Surg. 2014; 148:194-201.

2. Larrazabal LA, Selamet Tierney ES, Brown DW, Gauvreau K, Vida VL, Bergersen L, et al. Ventricular function deteriorates with recurrent coarctation in hypoplastic left heart syndrome. Ann Thorac Surg. 2008;86:869-74; discussion 873-4.
3. Biglino G, Giardini A, Ntsinjana HN, Schievano S, Hsia TY, Taylor AM, Modeling of Congenital Hearts Alliance Collaborative Group. Ventriculoarterial coupling in palliated hypoplastic left heart syndrome: noninvasive assessment of the effects of surgical arch reconstruction and shunt type. J Thorac Cardiovasc Surg. 2014;148:1526-33.

4. Bruse JL, Khushnood A, McLeod K, Biglino G, Sermesant M, Pennec X, et al; Modeling of Congenital Hearts Alliance Collaborative Group. How successful is successful? Aortic arch shape after successful aortic coarctation repair correlates with left ventricular function. J Thorac Cardiovasc Surg. 2017;153:418-27.

5. Bruse JL, Cervi E, McLeod K, Biglino G, Sermesant M, Pennec X, et al; Modeling of Congenital Hearts Alliance (MOCHA) Collaborative Group. Looks do matter! Aortic arch shape after hypoplastic left heart syndrome palliation correlates with cavopulmonary outcomes. Ann Thorac Surg. 2017;103:645-54.

6. Schäfer M, DiMaria MV, Jaggers J, Mitchell MB. Suboptimal neoaortic arch geometry correlates with inefficient flow patterns in hypoplastic left heart syndrome. J Thorac Cardiovasc Surg. 2019;158:e113-6. 